\title{
cagA positive and negative Helicobacter pylori strains are simultaneously present in the stomach of most patients with non-ulcer dyspepsia: relevance to histological damage
}

\author{
N Figura, C Vindigni, A Covacci, L Presenti, D Burroni, R Vernillo, T Banducci, \\ F Roviello, D Marrelli, M Biscontri, S Kristodhullu, C Gennari, D Vaira
}

Institute of Internal Medicine, University of Siena, Siena, Italy N Figura

M Biscontri

S Kristodhullu

C Gennari

Institute of Pathology, University of Siena

C Vindigni

L Presenti

IRIS, Siena

A Covacci

D Burroni

Institute of Surgical Clinics, University of Siena

$\mathrm{R}$ Vernillo

T Banducci

F Roviello

D Marrelli

Institute of Internal Medicine, University of Bologna, Bologna, Italy

D Vaira

Correspondence to: Dr N Figura, Institute of Internal Medicine,

University of Siena,

Policlinico Le Scotte, viale

Bracci, I-53100 Siena, Italy.

Accepted for publication 6 February 1998

\begin{abstract}
BackgroundIAims-Infection with Helicobacter pylori strains harbouring the cagA gene (cagA+) is associated with an increased risk of developing peptic ulcer and gastric cancer. The aim of this study was to assess whether $H$ pylori isolates with different cagA status were present in patients with non-ulcer dyspepsia, and whether a variable cagA status is relevant to histological gastric mucosal damage and glandular cell proliferation.
\end{abstract}

Methods-Well separated $H$ pylori colonies (between 2 and 25) from primary plates, per gastric area, for each of 19 patients with non-ulcer dyspepsia were examined for cagA by hybridisation. Western blotting was used to examine both representative colonies for CagA expression and the patients' sera for antibody response to CagA. Glandular gastric cell proliferation was assessed immunohistochemically.

Results-Of the 747 colonies examined, 45.3\% were cagA+. All colonies from four patients were cagA + , and all colonies from two patients were cagA-. In 13 patients (68\%) both cagA+ and cagA- colonies were found. CagA expression of isolates corresponded to their cagA status. $H$ pylori strains with different CagA molecular masses were present in three patients. Results based on all 19 patients studied showed that the prevalence of cagA+ colonies in areas with mucosal atrophy associated or not with intestinal metaplasia $(67.9 \%)$ was significantly higher than in normal mucosa $(44.7 \%)$ and mucosa from patients with chronic gastritis $(44.0 \%)(p<0.001)$. High levels of cell proliferation were associated with histological atrophy with or without intestinal metaplasia, but not with the possession of cagA by organisms colonising the same mucosal sites.

Conclusions-Most patients with nonulcer dyspepsia are infected by both cagA+ and cagA-H pylori colonies. The cagA status of infecting organisms may play a role in the development of atrophy and intestinal metaplasia.

(Gut 1998;42:772-778)

Keywords: gastritis; Helicobacter pylori infection; cagA; mucosal atrophy; cell proliferation
Helicobacter pylori is a spiral shaped microorganism which colonises the gastric epithelial cells of man and induces a local inflammation and local and systemic immune responses. If the infection persists, gastritis becomes chronic and lasts for a lifetime. The status of chronic inflammation of the gastric mucosa constitutes a determinant of gastroduodenal ulcerogenesis and a meaningful factor which increases the risk of developing gastric tumours (carcinoma and non-Hodgkin's lymphoma). ${ }^{1-3}$

$H$ pylori is a primary pathogen, as its presence on the gastric epithelium is almost always associated with a solid mucosal inflammatory response. However, isolates can range in their pathogenic potential. For instance, patients with peptic ulcer are mostly infected by cytotoxic strains, while those with superficial chronic gastritis and no ulcers are mostly infected by non-cytotoxic strains. ${ }^{4-7}$ Almost all cytotoxic strains also express a highly immunogenic protein called CagA, ${ }^{89}$ and recent studies have shown that patients with peptic ulceration, preneoplastic and neoplastic gastric epithelial lesions are more likely to be infected by CagA positive (CagA+) strains. $^{9-13}$ The enhanced pathogenic potential of CagA+ organisms seems to reside in the presence of a genomic insertion called cag which contains genes involved in virulence. ${ }^{14}$ Thus infection by cytotoxic or CagA expressing $H$ pylori strains exposes patients to an increased risk of contracting the most serious gastroduodenal diseases.

Some researchers have recently described the concomitant presence of cagA+ and cagA$H$ pylori organisms in the same patients. ${ }^{15-17}$ Mixed infections by phenotypically or genotypically different strains are not rare. For instance, cytotoxic and non-cytotoxic $H$ pylori strains were found at the same time in the same biopsy samples of about one third of the patients examined, ${ }^{11}$ and strains with the same ribotype were found in different gastric areas (antrum, corpus, and fundus) of single patients in only two of the 13 infected individuals examined. ${ }^{18}$ Cytotoxigenicity and the possession of the cagA gene are important characteristics which could enable these bacteria to preferentially colonise certain areas of the stomach where they may enjoy a selective benefit. Therefore, to obtain more insight into the epidemiology of cagA $+H$ pylori strains, we investigated: (a) whether patients with $H$ pylori related non-ulcer dyspepsia harboured in 
different areas of their stomachs strains that differed with respect to the presence of the cagA gene; (b) whether cagA+ strains preferentially colonised specific areas; $(c)$ whether the mucosal damage assessed histologically was related to the proportion of cagA+ colonies isolated from the same gastric site; and (d) whether levels of gastric glandular cell proliferation were related to the severity of the histological findings and/or to the possession of the cagA gene by the colonising $H$ pylori organisms.

\section{Methods}

STUDY POPULATION

The study was prospectively designed. The subjects were 19 adult non-consecutive patients with non-ulcer dyspepsia who were known to be $H$ pylori positive. The diagnosis of $H$ pylori infection was made by using a commercially available enzyme linked immunosorbent assay (ELISA) (Helicobacter pylori immunoglobulin G; Diesse, Siena, Italy). To avoid possible biases due to different clinical expressions of the infection, only patients without ulcerative and mucosal lesions suspected to be neoplastic on endoscopy were considered. Patients enrolled had not taken $\mathrm{H}_{2}$ antagonists or drugs that are potentially active on $\mathrm{H}$ pylori (including proton pump inhibitors) for three months and had a negative history of ulcer and cancer in the family.

ENDOSCOPY AND H PYLORI CULTURING AND IDENTIFICATION

During each endoscopy, biopsy specimens were taken from areas close together: four biopsy specimens were taken from the gastric antrum for culture, histology, rapid urease test, and microscopic examination after staining with carbol fuchsin; three specimens were taken from the corpus for culture, histology, and rapid urease test; two were taken from the fundus (in one case, only from the corpus and fundus, since the patient had undergone partial gastrectomy for Crohn's disease) for culture and histology. Forceps were disinfected and rinsed under running water between biopsies and were changed from one site to the other. Biopsy samples were transported in saline vials surrounded by melting ice, and seeded within four hours on to Columbia agar with $5 \%$ horse blood, $0.2 \%$ cyclodextrin, $10 \mathrm{mg} / 1$ trimethoprim, $5 \mathrm{mg} / \mathrm{l}$ vancomycin, $5 \mathrm{mg} / \mathrm{l}$ cefsoludin, and $5 \mathrm{mg} / \mathrm{l}$ amphotericin B. Plates were incubated in a microaerobic environment at $37^{\circ} \mathrm{C}$ for seven days and inspected daily from the third day for the presence of suspected colonies. Suspected colonies were identified as colonies of $H$ pylori if bacteria were Gram negative curved rods or spiral shaped organisms, were positive for oxidase, catalase and urease, and were susceptible to cephalothin and resistant to nalidixic acid (30 $\mu \mathrm{g}$ discs). ${ }^{19}$

HYBRIDISATION WITH cagA PROBE

A number (2 to 25) of well separated colonies on primary plates per gastric site per patient were subcultured on to the same medium for biopsy culture by the grid method. After four days of incubation in microaerobic conditions, the degree of growth on subculture was recorded. Colonies that were not fully developed were not taken into consideration for further assays. Subcultures were then replicated on to nitrocellulose membranes, denatured, and hybridised with the cagA probe. ${ }^{20}$ The probe was obtained by amplifying a nonvariable region of the cagA gene spanning nucleotides $1751-2048 .^{21}$ The primer D008 (5' - ATAATGCTAAATTAGACAACTTGAG CGA-3') and the primer R008 (5'-TTA GAATAATCAACAAACATCACGCCAT - 3') yields a product of $298 \mathrm{bp}^{21}$ through 40 consecutive amplification cycles: initial denaturation, five minutes at $94^{\circ} \mathrm{C}$ (one cycle); denaturation, one minute at $94^{\circ} \mathrm{C}$; primer annealing, one minute at $60^{\circ} \mathrm{C}$; extension, one minute at $72^{\circ} \mathrm{C}$ (38 cycles); denaturation, one minute at $94^{\circ} \mathrm{C}$; primary annealing, one minute at $60^{\circ} \mathrm{C}$ (one cycle); extension, five minutes at $72^{\circ} \mathrm{C}$. The probe was radiolabelled with ${ }^{32} \mathrm{P}$ using the Random Primed DNA Labelling kit provided by BoehringerMannhein Italia SpA, Milan, Italy. Hybridisation was carried out overnight at $65^{\circ} \mathrm{C}$. After two washes at $65^{\circ} \mathrm{C}$ in $2 \times \mathrm{SSC}$ (where $1 \times \mathrm{SSC}$ is $0.15 \mathrm{M} \mathrm{NaCl}+0.015 \mathrm{M}$ sodium citrate) with $0.2 \%$ sodium dodecyl sulphate, the blots were exposed to XAR-5 Kodak film overnight at $-80^{\circ} \mathrm{C}$. $H$ pylori CCUG 17874 was included in each assay as a positive control for cagA, and strain G21 as a negative control. ${ }^{21}$

ASSAY OF CagA EXPRESSION

One third of the bacterial growth from the first subcultured colony per gastric site per patient was examined for the expression of the cagA genomic product by the Western blotting technique. Bacterial suspensions with a density approximately equivalent to Mac Farland 6 opacity standard were lysed and denatured in Laemmli solution at $100^{\circ} \mathrm{C}$ for five minutes, ${ }^{22}$ and $5 \mu \mathrm{l}$ each denatured sample was run electrophoretically in $10 \%$ polyacrylamide gel with sodium dodecyl sulphate. ${ }^{22}$ Proteins were transferred on to nitrocellulose sheets that were saturated with 3\% defatted milk in phosphate buffered saline (PBS) with $0.1 \%$ Triton $\mathrm{X}$ (blotto). Sheets were incubated overnight at room temperature with anti-CagA and antiurease polyclonal antibodies, obtained by immunising rabbits with recombinant CagA protein $^{21}$ and purified $H$ pylori urease respectively, at dilutions of $1: 2000$ and $1: 8000$ in blotto respectively. After two washes in blotto, samples were incubated at room temperature for 90 minutes with an anti-rabbit immunoglobulin $G$ antibody labelled with peroxidase. The reaction was visualised with the enhanced chemiluminescence Western blotting detection system (Amersham). The type strain CCUG 17874 and strain G21 were respectively used as positive and negative controls. For detection of strains from the same patient with CagA migrating at different levels, the assay was repeated and CagA molecular mass was estimated by comparison with those of strains CCUG 17874 and G39, which are 128 and $136 \mathrm{kDa}$ respectively. ${ }^{8}$ 
DETECTION OF ANTI-CagA ANTIBODY

A whole cell suspension of $H$ pylori strain CCUG $17874(\mathrm{CagA}+)$ was lysed and denatured in Laemmli buffer at $100^{\circ} \mathrm{C}$ for five minutes $^{22}$ and then electrophoresed in $10 \%$ polyacrylamide gel with sodium dodecyl sulphate. Proteins were transferred to nitrocellulose sheets which were saturated with blotto. Strips were cut, and serum samples were assayed at a dilution of 1:200 in blotto. After overnight incubation at room temperature, strips were washed with blotto, and then incubated with an anti-human immunoglobulin $G$ serum conjugated with peroxidase at room temperature for 90 minutes. After washing, the reaction was visualised by adding the substrate $\left(\mathrm{H}_{2} \mathrm{O}_{2}\right.$ in a solution of 4-chloro-1-naphthol in $0.05 \mathrm{M}$ Tris/ $\mathrm{HCl}$ buffer, $\mathrm{pH}$ 6.8). As positive and negative controls, we used serum samples from two patients infected with respectively CagA+ and CagA- $H$ pylori strains (several colonies per patient had been examined), and with and without antibodies to CagA respectively. In addition, the positive control serum did not react with any antigen at the level of the CagA molecular mass $(120-140 \mathrm{kDa})^{8}$ (data not shown).

\section{HISTOLOGY}

Gastric biopsy specimens were placed in $10 \%$ buffered formalin and routinely processed. Sections were stained with haematoxylin and eosin and by a modified Giemsa method to detect $H$ pylori. Inflammation, activity, and other mucosal alterations, such as gland atrophy and intestinal metaplasia, were evaluated semiquantitatively by the Sidney System by two pathologists.

ASSAY OF GASTRIC CELL PROLIFERATION

An immunohistochemical study was performed to determine gastric cell proliferation by evaluating the expression of the proliferative cell nuclear antigen (PCNA), using the APAAP method. In brief, $4 \mu \mathrm{m}$ thick sections of paraffin embedded biopsy specimens were dewaxed and rinsed in PBS $(50 \mathrm{mM}$ Tris/ $\mathrm{HCl}, \mathrm{pH} 7.6$, in $0.15 \mathrm{M} \mathrm{NaCl}$ ). Sections were then incubated overnight with primary monoclonal antiPCNA antibody (PC10; murine IgG2a; Dako, Milan, Italy) at a 1:30 dilution. The sections were washed in PBS and incubated with biotinylated rabbit anti-mouse serum (Dako) diluted 1:30, for 30 minutes. The sections were rinsed again in PBS, and the alkaline phosphatase/anti-alkaline phosphatase complex (APAAP, D651; Dako) at a 1:50 dilution was applied for 30 minutes. After a wash in PBS, New Fuchsin was layered on to the biopsy specimen as a chromogen and the mixture incubated for 25 minutes. The sections were then washed in distilled water and counterstained with haematoxylin, dehydrated, and mounted with an aqueous mounting medium (Aquatex; Merck, Darmstadt, Germany). Only gastric pits perpendicular to the epithelial surface were analysed. Each gland was scored for PCNA immunoreactivity under a light microscope at $\times 400$ magnification. The PCNA labelling index is defined as the proportion of positively immunostaining nuclei expressed as a percentage of the total nuclei counted. Gastric mucosa glands were divided into upper, middle (isthmus), and lower regions. The PCNA labelling index was also calculated for each region of the gland.

STATISTICS

Proportions were compared in univariate analysis by $\chi^{2}$ test with Yates's correction, the Fisher's exact test, the $t$ test for independent samples, and the Mann-Whitney rank sum test, according to the case. A multivariate analysis was performed with a multiple regression model in which the proliferation index of glandular neck cells was the dependent variable, and the covariates were the percentage of cagA+ colonies per biopsy (as a continuous variable), the histological findings (normal, simple chronic gastritis, chronic gastritis with atrophy/intestinal metaplasia), and the gastric site (antrum, corpus, fundus). $\mathrm{p}<0.05$ was considered significant.

\section{Results}

STUDY POPULATION

Table 1 lists the patients studied, together with other details. The mean (SD) age was 57.42 (16.59) years, range $27-87$ years.

\section{CULTURE}

To determine the extent of colonisation of $H$ pylori, biopsy specimens from different parts of the stomach were cultured. A total of 56 biopsy samples were cultured, and 54 samples were found to be $H$ pylori positive (table 1 ). $H$ pylori organisms were isolated from the three gastric areas (two areas in the patient with partial gastrectomy) in 17 of the 19 patients examined. One antral specimen and one fundic specimen from another patient were culture negative (table 1).

DETECTION OF THE cagA GENE BY HYBRIDISATION The purpose of this assay was to investigate the possible simultaneous presence in the stomach of individual patients of strains that differed with respect to possession of the cagA gene, and to determine whether cagA+ bacteria have preferential areas of colonisation. Table 1 gives the number of cagA+ and cagA- colonies from each patient at each site. A total of $747 \mathrm{H}$ pylori colonies isolated from 54 culture positive biopsy samples were examined for cagA. In total, 339 colonies $(45.4 \%)$ were cagA $+: 45.8 \%$ of colonies (108 of 236) from biopsy specimens taken from the antral sites, $51.4 \%$ of colonies (141 of 274) from the corpus sites, and $42.2 \%$ of colonies (100 of 237) from the fundic sites. These percentages were not significantly different when corrections were made for multiple comparisons ( $\chi^{2}$ with Bonferroni correction). All colonies from biopsy samples of patients 2 , 5,9 , and 15 (table 1) were cagA+; all colonies from patients 14 and 17 (table 1) were cagA-. In the remaining 13 cases $(68 \%), c a g A+$ and cagA- organisms were present at the same time. There were two patients in this group (patients 1 and 10) in whom colonies from one or two gastric sites were cagA- while those 
Table 1 Data pertinent to the patients studied, and results of histology, the possession of cagA by $H$ pylori colonies, and the proliferation of glandular isthmus cells, per patient, at each site

\begin{tabular}{|c|c|c|c|c|c|c|c|c|c|}
\hline \multirow{2}{*}{$\begin{array}{l}\text { Patients and age } \\
\quad \text { (in years) }\end{array}$} & \multicolumn{3}{|c|}{ Histological findings in the three gastric sites } & \multicolumn{3}{|c|}{$\begin{array}{l}\text { No of cagA } A+\text { colonies out of } \\
\text { colonies tested per site }\end{array}$} & \multicolumn{3}{|c|}{ Growth labelling index per site } \\
\hline & $A$ & $C$ & $F$ & $A$ & $C$ & $F$ & $A$ & $C$ & $F$ \\
\hline $1(28)$ & MG & MG & MG & $0 / 20$ & $0 / 17$ & $11 / 11$ & 14 & 12 & 10 \\
\hline $2(51)$ & 1 & MAcG & MG & 1 & $5 / 5$ & $5 / 5$ & 1 & 26 & 4 \\
\hline $3(64)$ & $\mathrm{N}$ & $\mathrm{N}$ & $\mathrm{N}$ & $1 / 12$ & $15 / 16$ & $7 / 11$ & 18 & 7 & 7 \\
\hline $4(27)$ & MG & MG & MG & $16 / 16$ & $20 / 22$ & $17 / 25$ & 11 & 7 & 3 \\
\hline $5(75)$ & MoGAtIm & MoGAtIm & MG & $4 / 4$ & $6 / 6$ & NBG & 27 & 34 & 7 \\
\hline $6(87)$ & MoGAtD & MoG & MoG & $16 / 16$ & $18 / 21$ & $6 / 13$ & 37 & 21 & 15 \\
\hline $7(74)$ & AtIm & MoGAtI m & SGAc & NBG & $7 / 9$ & $1 / 18$ & 16 & 18 & 25 \\
\hline $8(54)$ & MG & MG & MG & $8 / 8$ & $7 / 8$ & $2 / 3$ & 7 & 6 & 6 \\
\hline $9(58)$ & MG & $\mathrm{N}$ & $\mathrm{N}$ & $8 / 8$ & $4 / 4$ & $8 / 8$ & 12 & 5 & 9 \\
\hline $10(57)$ & $\mathrm{N}$ & MG & MG & $2 / 16$ & $2 / 13$ & $0 / 7$ & 5 & 16 & NP \\
\hline $11(47)$ & MG & $\mathrm{N}$ & MG & $16 / 20$ & $19 / 20$ & $4 / 20$ & 12 & 14 & 18 \\
\hline $12(83)$ & MG & $\mathrm{N}$ & MG & $5 / 20$ & $6 / 20$ & $7 / 20$ & NP & NP & NP \\
\hline $13(37)$ & MoG & $\mathrm{N}$ & $\mathrm{N}$ & $5 / 20$ & $1 / 20$ & $2 / 20$ & 19 & 6 & 6 \\
\hline $14(70)$ & MG & MG & MG & $0 / 10$ & $0 / 10$ & $0 / 10$ & 5 & 13 & 8 \\
\hline $15(62)$ & MoGAt & MG & $\mathrm{N}$ & $8 / 8$ & $20 / 20$ & $16 / 16$ & 13 & 5 & 4 \\
\hline $16(62)$ & MG & MoGAtImD & MG & $6 / 13$ & $1 / 12$ & $1 / 2$ & 8 & 16 & 15 \\
\hline $17(53)$ & MoG & MG & $\mathrm{N}$ & $0 / 19$ & $0 / 20$ & $0 / 18$ & 24 & 8 & 6 \\
\hline $18(43)$ & MGAtIm & MG & MG & $3 / 16$ & $4 / 18$ & $4 / 16$ & 22 & 15 & 16 \\
\hline $19(59)$ & MGAtIm & MG & MG & $10 / 10$ & $6 / 13$ & $3 / 14$ & 12 & 11 & 5 \\
\hline
\end{tabular}

A, antrum; C, corpus; F, fundus; N, normal mucosa; G, chronic gastritis; M, mild; Mo, moderate; S, severe; Ac, active; At, atrophy; Im, intestinal metaplasia; D, dysplasia; /, in this patient, the antrum was resected; NBG, no bacterial growth; NP, not performed.

from other sites were cagA+ or mixed, and four patients (patients 4, 6, 8, and 19) in whom colonies from a single site were cagA+, while those from other sites were mixed, cagA+ and cagA- (table 1). Figure 1 shows an example of the presence of both cagA+ and cagA- colonies in the same patient.

EXPRESSION OF CagA

This test was carried out to see whether the possession of the cagA gene corresponded to the expression of the CagA protein. The number of culture positive biopsy samples was 54; therefore a total of 54 strains was examined. The expression of CagA agreed with

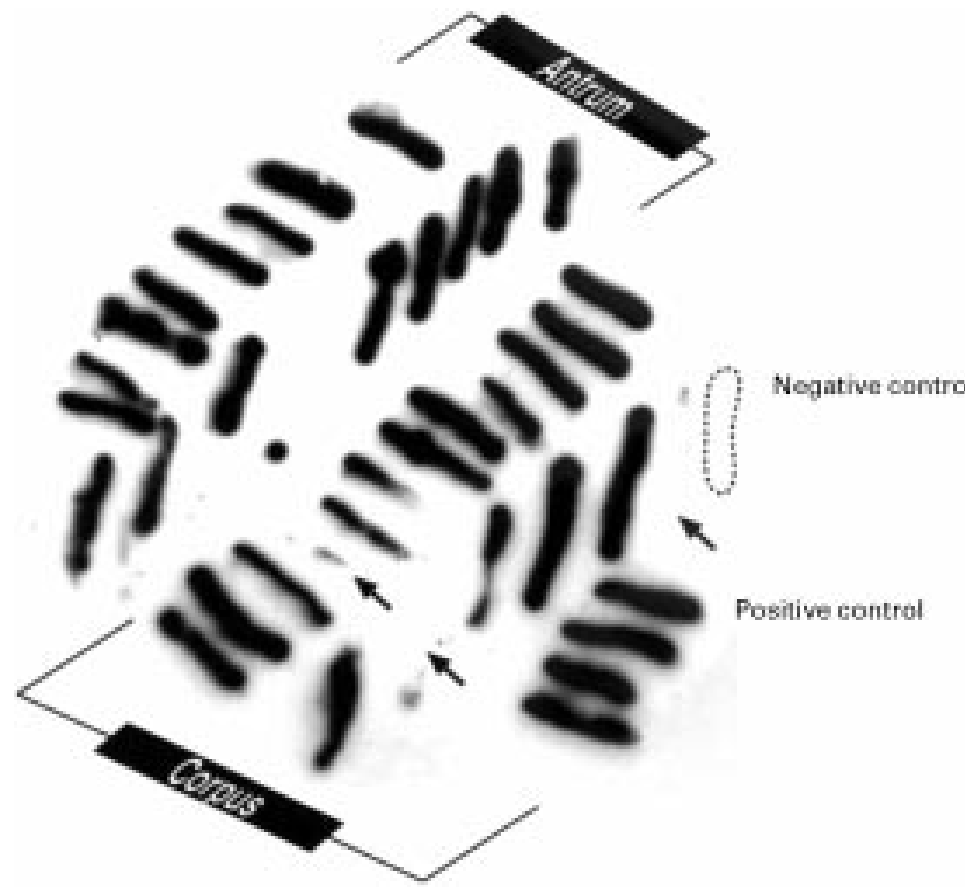

Figure 1 Hybridisation with cagA probe of subcultures of different $H$ pylori colonies from primary plates streaked with biopsy samples taken from two gastric areas from the same patient. All 16 colonies from the antrum and 18 of 21 from the corpus are cagA+ (six of 13 colonies from the fundus were cagA+; data not shown). The arrows indicate the cagAcolonies. the possession of the cagA gene in all cases. All 15 cagA- strains tested failed to produce the protein. In three cases, the CagA molecular mass of the strain isolated from one site was different from that of strains isolated from the other sites of the same patients (fig 2). For instance, of the three strains isolated from a single patient, the strain in fig 2 , lane 1 was CagA negative, and strains in lanes 2 and 3 were positive, with CagA molecular masses of about 135 and $130 \mathrm{kDa}$ respectively.

DETECTION OF ANTI-CagA ANTIBODIES

The test was carried out to see whether there was any correspondence between the presence of $H$ pylori colonies that possessed cagA and the anti-CagA antibody response in each patient. All patients but one (95\%) had antibodies to CagA (data not shown). One of the two patients in whose biopsy specimen there were only cagA- colonies showed a week positivity for CagA.

\section{HISTOLOGY}

Table 1 gives the histological data. Normal mucosa was found in 12 of the 56 biopsy samples examined histologically, chronic gastritis with no other lesion was observed in 35 , and

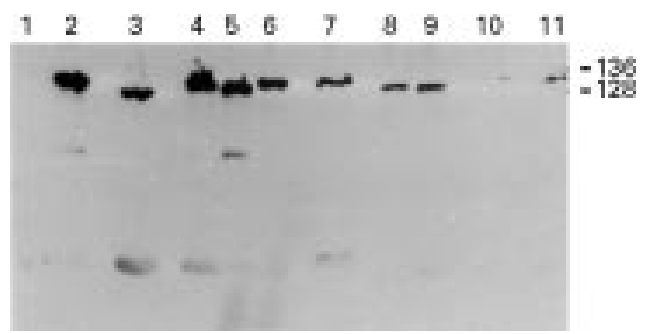

Figure 2 Western blots showing, in three cases (lanes 1-3, 4-6, and 7-9), the simultaneous presence of $H$ pylori strains with different CagA molecular mass in different areas of single patients. The strain in lane 1 was cagA-. The strains in lanes 10 and 11 were two cag $A+H$ pylori strains of similar CagA molecular mass isolated from two different gastric areas of a patient. The numbers on the right are the molecular masses in $\mathrm{kDa}$ of $\mathrm{H}$ pylori strains CCUG 17874 and G39. 
mild or moderate atrophy found in nine, in seven of which concomitant intestinal metaplasia was found and in one dysplasia.

\section{PROPORTION OF cagA+ COLONIES AND}

HISTOLOGICAL FINDINGS

This correlation was made to see whether a relation existed between the presence of strains that harboured the cagA gene and the degree of histological damage of the colonised gastric mucosa. The percentages of cagA+ strains from culture positive sites-that is 12 areas with histologically normal mucosa, 34 with mild/moderate chronic gastritis, and eight with glandular atrophy (in six associated with intestinal metaplasia) - were 44.7, 44.0 and 67.9 respectively $(\mathrm{p}=0.0001$, atrophy/intestinal metaplasia $v$ gastritis, odds ratio $=2.69$, relative risk $=1.52)$ (table 2$)$. All colonies isolated from six of eight culture positive biopsy samples taken from gastric sites with atrophy, from five of 34 from sites with chronic gastritis without other lesions, and from three of 12 from normal mucosa (table 1) were cagA+ $(\mathrm{p}=$ 0.039 , atrophy $v$ normal mucosa; $\mathrm{p}=0.001$, atrophy $v$ chronic gastritis alone; $\mathrm{p}=0.347$, chronic gastritis $v$ normal mucosa (not significant); Fisher's exact test).

\section{CELLULAR PROLIFERATION AND HISTOLOGICAL} FINDINGS

We aimed to see whether increased proliferation of cells was related to histological damage, the presence of colonies harbouring the cagA gene, or the gastric site. Table 3 gives the cumulative labelling index values. Both total and isthmus labelling index values in biopsy specimens with atrophy/intestinal metaplasia32.67 (10.46) and 21.67 (9.10) respectively (means (SD)) - were significantly higher than in those with chronic gastritis alone- 17.97 (7.89) and 11.34 (6.01) respectively - or with normal mucosa (table 3). As far as the glandular base labelling index is concerned, no significant difference was found (data not reported). The difference in labelling index in chronic gastritis and in normal mucosa sam-

Table 2 Prevalence of cagA + colonies from dyspeptic patients in relation to histological findings

\begin{tabular}{lllc}
\hline Histology & $\begin{array}{l}\text { No of culture positive } \\
\text { specimens }\end{array}$ & $\begin{array}{l}\text { No of colonies tested for } \\
\text { cagA }\end{array}$ & $\begin{array}{l}\text { No (\%) of cagA+ } \\
\text { colonies }\end{array}$ \\
\hline $\begin{array}{l}\text { Normal mucosa } \\
\text { Chronic gastritis }\end{array}$ & 12 & 181 & $81(44.7)$ \\
$\begin{array}{l}\text { Atrophy/intestinal } \\
\text { metaplasia }\end{array}$ & 34 & 485 & $214(44.0)$ \\
\hline
\end{tabular}

$\mathrm{p}=0.95$ (NS) normal mucosa $v$ chronic gastritis; $\mathrm{p}=0.0008$ normal mucosa $v$ atrophy/intestinal metaplasia; $\mathrm{p}=0.0001$ chronic gastritis $v$ atrophy/intestinal metaplasia.

Table 3 Proliferation of gastric glandular cells of culture positive biopsy samples according to histological findings

\begin{tabular}{llll}
\hline Histology & $\begin{array}{l}\text { No of samples } \\
\text { examined }\end{array}$ & $\begin{array}{l}\text { Isthmus labelling } \\
\text { index }\end{array}$ & Total labelling index \\
\hline $\begin{array}{l}\text { Normal mucosa } \\
\text { Chronic gastritis }\end{array}$ & 12 & $7.82(4.35)$ & $12.64(7.90)$ \\
$\begin{array}{l}\text { Atrophy/intestinal } \\
\text { metaplasia }\end{array}$ & 84 & $11.34(6.01)$ & $17.97(7.89)$ \\
\hline
\end{tabular}

Values expressed as mean (SD)

Isthmus labelling index: $\mathrm{p}=0.082$ (NS) normal mucosa $v$ chronic gastritis; $\mathrm{p}<0.001$ chronic gastritis $v$ atrophy/intestinal metaplasia. Total labelling index: $\mathrm{p}=0.061$ (NS) normal mucosa $v$ chronic gastritis; $\mathrm{p}<0.001$ chronic gastritis $v$ atrophy/intestinal metaplasia. ples was not significant. To rule out the possibility that the gastric site per se could have an influence on cell proliferation, the labelling index of cells from biopsy specimens from patients with only chronic gastritis (without atrophy), taken from the antrum, corpus, and fundus areas, were compared by univariate analysis, but the differences were not significant (data not shown).

PROPORTION OF cagA + COLONIES AND CELL PROLIFERATION

This correlation was attempted to verify whether the levels of glandular cell proliferation were influenced by the number of colonies of $H$ pylori organisms possessing cagA. No significant difference was found in the cell proliferation indexes in biopsy samples taken from areas of the stomach colonised by all cagA+ or all cagA- helicobacters-13.21 (9.5) and 11.25 (6.11) respectively. The labelling index in samples colonised by both cagA+ and cagAcolonies was 12.30 (6.15).

The results obtained by univariate analysis were confirmed by a multiple linear regression model, which showed that the only variable that was independently associated with a high proliferative gastric glandular cell score-that is, histological findings, proportion of cagA+ colonies, and gastric sites - was histology - that is, the presence of atrophy/intestinal metaplasia $(\mathrm{p}<0.001)$.

\section{Discussion}

$H$ pylori infection is an important determinant of peptic ulceration and gastric neoplasm development. The variation in frequency of such diseases may in part depend on differences in cytotoxin production and possession of the cagA gene by $H$ pylori. ${ }^{49101213}$ Most studies on the pathogenic potential of these factors have been carried out by examining only one colony, or pooled colonies, of $\mathrm{H}$ pylori per patient on a single occasion, or by determining the local or the systemic immune response to the vacuolating toxin or the CagA protein. However, seropositivity for VacA and CagA does not determine the composition of the bacterial population in the stomach, and the characteristics of a single clone cannot be extrapolated to all the helicobacters colonising the same organ. As there is evidence that bacterial phenotypic variety and genomic macroor micro-diversity can exist within the stomach of a single patient, ${ }^{11} 1823$ it was important to determine whether strains with different expression of cagA could colonise the same patients at the same time. A number of investigators have tackled this problem, but we believe that the frequency of mixed cultures that they observed was probably underestimated, ${ }^{915-18}$ partly because, in some cases, pooled colonies had been stored at $-70^{\circ} \mathrm{C}$ before the tests were carried out. To avoid the possibility of our results being skewed by differences in culture efficiency of pooled cag $A+$ and cagA- strains, we tested for cagA in several well separated colonies from primary plates per patient. Our results, showing that two thirds of patients harboured both cagA+ and cagA- organisms, are 
compatible with those obtained by van der Ende $e t a l^{16}$ on members of a single family (four of seven members harboured cagA+ and cagAcolonies), and are supported by an earlier study on genomic variety of $H$ pylori strains isolated from different gastric sites of the same patients, a study that showed that $85 \%$ of 13 Italian patients were colonised by strains with different ribotypes. ${ }^{18}$ The latter study, however, also suggests that cagA+ and cagA- organisms from the same patient may be different strains. ${ }^{18}$ It is difficult to decide whether strains that differ with respect to cagA status are substantially genomically different clones or just variants within a population: two concomitant genomically different strains may both possess the cagA gene, ${ }^{15}$ and, vice versa, strains from the same patient, with identical fingerprinting patterns after polymerase chain reaction, may differ in their cagA status. ${ }^{16}$

The high prevalence of $c a g A$ status observed in our patients $(89.4 \% v 60 \%$ in other studies performed in Western countries) ${ }^{69}$ may possibly be explained by genetic predisposition ${ }^{24}$ and/or a particularly virulent cagA+ strain in this area. This province of Tuscany is inhabited by a population that was relatively segregated up until a few years ago, which could have resulted in selection of particularly virulent strains and favoured their transmission. The high frequency of $c a g \mathrm{~A}+$ status in our patients with non-ulcer dyspepsia may be compatible with the elevated incidence of gastric cancer in Tuscany: 57.3/100 000/year in 1990 (the most recent data), ${ }^{25}$ and is in accord with the observation of an increased risk of gastric cancer in individuals infected by cagA $+H$ pylori, compared with those infected by cagA- strains, $^{26}$ and, more generally, in individuals who live in areas with virulent cagA $+H$ pylori strains. ${ }^{13}$

Western blotting results confirmed that all cagA+ and no cagA- strains examined produced a protein that reacted immunologically with a rabbit serum raised to a recombinant CagA of the type strain CCUG 17874. This result indicates that the cagA gene almost always expresses its product in our isolates. Thus the fact that one patient with only cagAorganisms in his stomach tested positive for CagA may indicate an additional, current or past, case of mixed infection (in our experience, a systemic antibody response to CagA can be maintained for up to three years after $H$ pylori infection has been cured (data not shown)).

In the stomach of each of three patients with cagA mixed infections and with a predominance of cagA + colonies, we have noticed the presence of strains that expressed CagA of different molecular mass (fig 2). The meaning of such a finding is not clear. Variation in CagA molecular mass depends on the presence of nucleotide repeats inside the cagA gene. ${ }^{21}$ As CagA molecular mass is stable even after repeated subcultures ${ }^{8}$ (N Figura, personal observation), strains with CagA of different molecular mass from the same subject may be considered to be different. This observation further complicates the problem of the ge- nomic variability between $H$ pylori isolates from single patients.

A high frequency of cagA + colonies was found in areas of gastric atrophy, whereas in areas of normal mucosa cagA+ colony frequency was similar to that found in areas of inflamed mucosa without atrophy. This finding may suggest that the pathogenic potential of cagA+ strains on the gastric mucosa may be exerted in full only when cagA+ colonies make up the majority of the organisms colonising a particular gastric area.

In the present study, as well as in previous investigations, ${ }^{27-29}$ the proliferation index of isthmus and total glandular cells in gastric areas with mucosal atrophy was significantly higher than that in normal mucosa and in areas of chronic gastritis without atrophy. Despite high proliferation scores having been reported in infection with cytotoxic strains, ${ }^{30}$ - that is, with strains mostly expressing $\mathrm{CagA}^{8}$-we found no statistical difference in cell proliferation in relation to the cagA status of the colonising organisms.

The key mechanism that regulates the growth of the gastric cells is not completely clear. In the literature, there are contradictory results on the role that cytotoxin production and/or cagA status of isolates plays in accelerated gastric cell replication, either in vivo or in vitro. $^{30-33}$ CagA or factors co-expressed by cagA+ organisms may contribute to the conditions, such as atrophy and metaplastic transformation, characterised by accelerated cell growth. ${ }^{34}$ Once these highly proliferative mucosal states have been established, increased PCNA expression may persist independently of cagA. We therefore hypothesise that strains with the pathogenicity island cag, the cagA of which is a component and the marker, may not have as strong an influence in the later stages of the disease.

In conclusion, we found that most $H$ pylori positive patients with non-ulcer dyspepsia are infected with cagA+ and cagA- organisms at the same time. We believe that this variable cagA status may be relevant to the clinical outcome of infection. In any case, a comparison between the prevalence of strains with certain genomic virulence determinants from different patients requires analysis of multiple isolates selected from primary plates.

We are indebted to Ms Laura Bianciardi (Library Assistant, University of Siena Library) for her help, and to Ms Ruth Colapinto, manager of Villa Cetinale, Sovicille (Siena), for correcting the English.

1 Blaser MJ. Gastric campylobacter-like organisms, and peptic ulcer disease. Gastroenterology 1987;93:371-83. 2 Parsonnet J, Friedman GD, Vandersteen DP, et al. Helicobacter pylori infection and the risk of gastric carcinoma. N Engl F Med 1991;325:1127-31

3 Wotherspoon, AC, Ortiz Hidalgo C, Falzon MR, et al. Helicobacter pylori-associated gastritis and primary B-cell gastric carcinoma. Lancet 1991;338:1175-6.

4 Figura N, Guglielmetti P, Rossolini A, et al. Cytotoxin production by Campylobacter pylori strains isolated from patients with peptic ulcer and from patients with chronic gastritis only. FClin Microbiol 1989;27:225-6.

5 Goossens H, Glupczynski Y, Burette A, et al. Role of the vacuolating toxin from Helicobacter pylori in the pathogenesis of duodenal and gastric ulcer. Medical Microbiology Letters 1992;1:153-9.

6 Crabtree JE, Taylor JD, Wyat JI, et al. Mucosal IgA recognition of Helicobacter pylori $120 \mathrm{kDa}$ protein, peptic ulceration, and gastric pathology. Lancet 1991;338:332-5. 
7 Phadnis SH, Ilver D, Janzon L, et al. Pathological significance and molecular characterization of the vacuolating toxin gene of Helicobacter pylori. Infect Immun 1994;62:1557-65.

8 Xiang Z, Censini S, Bayeli PF, et al. Analysis of expression of $\mathrm{CagA}$ and VacA virulence factors in 43 strains of Helicobacter pylori reveals that the clinical isolates can be divided into two major types and that CagA is not necessary for expression of the vacuolating toxin. Infect Immun 1995;63:94-8.

9 Weel JFL, van der Hulst RWM, Gerrits Y, et al. The interrelationship between cytotoxin-associated gene A, vacuolating cytotoxin, and Helicobacter pylori-related diseases. $\mathcal{F}$ Infect Dis 1996;173:1171-5.

10 Oderda G, Figura N, Bayeli PF, et al. Serologic IgG recognition of Helicobacter pylori cytotoxin-associated protein, peptic ulcer and gastroduodenal pathology in childhood. Eur 7 Gastroenterol Hepatol 1993;5:695-9.

11 Figura N, Bugnoli M, Cusi MG, et al. Pathogenic mechanisms of Helicobacter pylori: production of cyto-
toxin. In: Malfertheiner P, Ditschuneit H, eds. Helicobacter toxin. In: Malfertheiner $\mathrm{P}$, Ditschuneit $\mathrm{H}$, eds. Helicobacter pylori, gastritis and peptic ulcer.

12 Kuipers EJ, Pérez-Pérez GI, Meuwissen SGM, et al. Helicobacter pylori and atrophic gastritis: importance of the cag $A$ status. F Natl Cancer Inst 1995;87:1777-80.

13 Blaser MJ, Pérez-Pérez GI, Kleanthous $\mathrm{H}$, et al. Infection with Helicobacter pylori strains possessing cag $A$ is associated with an increased risk of developing adenocarcinoma of the stomach. Cancer Res 1995;55:2111-15.

14 Censini S, Lange C, Xiang Z, et al. cag, a pathogenicity island of Helicobacter pylori, encodes type I-specific and disease-associated virulence factors. Proc Natl Acad Sci USA 1996;93:14648-53.

15 Fantry GT, Zheng QX, Darwin PE, et al. Mixed infection with $\operatorname{cag} A$ positive and $\operatorname{cag} A$ negative strains of Helicobacter pylori. Helicobacter 1996;1:98-106.

16 van der Ende A, Rauws EAJ, Feller M, et al. Heterogeneous Helicobacter pylori isolates from members of a family with Helicobacter pylori isolates from members of a family with a history

17 Taylor NS, Fox JG, Akopyants NS, et al. Long-term colonization with single and multiple strains of Helicobacter pylori assessed by DNA fingerprinting. f Clin Microbio 1995;33:918-23.

18 Owen RJ, Desai M, Figura N, et al. Comparison between degree of histological gastritis and DNA fingerprints, cytotoxicity and adhesivity of Helicobacter pylori from differen gastric sites. Eur F Epidemiol 1993;9:315-21

19 Glupczynski Y. Culture of Helicobacter pylori from gastric biopsies and antimicrobial susceptibility testing. In: Lee A Mégraud F, eds. Helicobacter pylori: techniques for clinical diagnosis and basic research. London: Saunders, 1966:1732 .

20 Maniatis T, Fritsch EF, Sambrook J. Molecular cloning: a laboratory manual. 2nd ed. Plainview, NY: Cold Spring Harbor Laboratory Press, 1989.
21 Covacci A, Censini S, Bugnoli M, et al. Molecular characterization of the $128-\mathrm{kDa}$ immunodominant antigen

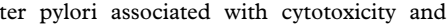
duodenal ulcer. Proc Natl Acad Sci USA 1993;90:5791-5.

22 Laemmli UK. Cleavage of structural proteins during the assembly of the head of bacteriophage T4. Nature 1970;227:680-5.

23 Jorgensen M, Daskalopoulos G, Warburton V, et al. Multiple strain colonization and metronidazole resistance in Helicobacter pylori-infected patients: identification from sequential and multiple biopsy specimens. F Infect Dis 1996;174: 631-5.

24 Parsonnet J, Replogle M, Yang S, et al. Seroprevalence of CagA-positive strains among Helicobacter pylori-infected, healthy young adults. F Infect Dis 1997;175:1240-2.

25 Balzi D, Bidoli E, Franceschi S, et al. Estimates of cancer incidence and mortality in Italian Regions 1990. Associazione Italiana Registri Tumori A.I.R.T., 1997:36.

26 Parsonnet J, Friedman GD, Orentreich N, et al. Risk for gastric cancer in people with CagA positive or CagA negative Helicobacter pylori infection. Gut 1997;40:297-301.

27 Muñoz N, Kato I, Peraza S, et al. Prevalence of precancerous lesions of the stomach in Venezuela. Cancer Epidemiol Biomarkers Prev 1996;5:41-6.

28 Correa P, Ruiz B, Shi T-Y, et al. Helicobacter pylori and nucleolar organizer regions in the gastric antral mucosa. Am f Clin Pathol 1994;101:656-60.

29 Bechi P, Balzi M, Becciolini A, et al. Helicobacter pylori and cell proliferation of the gastric mucosa: possible implication for gastric carcinogenesis. Am f Gastroenterol 1996;91:2716.

30 De Koster E, Lage A, Buset M, et al. Influence of HP vacuolating toxin on gastric antrum and corpus mucosal cell proliferation status. Acta Gastroenterol Belg 1993;68 (suppl):

31 Ricci V, Ciacci C, Zarrilli R, et al. Effect of Helicobacter pylori on gastric epithelial cell migration and proliferation in vitro: role of VacA and CagA. Infect Immun 1996;64: 2829-33.

32 Sandor Z, Vincze Á, Jadus M, et al. Effect of vac+ and vacHelicobacter pylori $(\mathrm{Hp})$ supernatants on the bioactivity of basic fibroblast growth factor (bFGF) and platelet-derived growth factor (PDGF) in vitro. Gastroenterology 1996;110 (suppl):A249.

33 Brännström J, Zachrisson K, Engstrand L, et al. Helicobacter pylori stimulates DNA synthesis in a small intestinal cell line. Gastroenterology 1996;110(suppl):A871

34 Beales IL, Crabtree JE, Scunes D, et al. Antibodies to CagA are associated with gastric atrophy in Helicobacter pylori infection. Eur f Gastroenterol Hepatol 1996;8:645-9.

35 Ito S, Azuma T, Murakita H, et al. Profile of Helicobacter pylori cytotoxin derived from two areas of Japan with different prevalence of atrophic gastritis. Gut 1996;39:800- 